\title{
Choroidal Fissure Cerebrospinal Fluid-Containing Cysts: Case Series, Anatomical Consideration, and Review of the Literature
}

\section{Lars de Jong ${ }^{1}$, Liesbeth Thewissen ${ }^{2}$, Johannes van Loon ${ }^{1}$, Frank Van Calenbergh ${ }^{1}$}

\author{
Key words \\ - Arachnoid cyst \\ - Choroidal fissure \\ - Neuroepithelial cyst
}

\section{Abbreviations and Acronyms}

ADHD: Attention deficit hyperactivity disorder CSF: Cerebrospinal fluid

CT: Computed tomography

MR: Magnetic resonance

From the Departments of ${ }^{\mathbf{1}}$ Neurosurgery and
${ }^{2}$ Neonatology, University Hospitals Leuven,
Leuven, Belgium
To whom correspondence should be addressed:
Lars de Jong, M.D. [E-mail: lars.dejong@uzleuven.be]
Citation: World Neurosurg. (2011) 75, 5/6:704-708.
DOI: 10.1016/j.wneu.2010.12.056
Journal homepage: www.WORLDNEUROSURGERY.org
Available online: www.sciencedirect.com
1878-8750/\$ - see front matter (C) 2011 Elsevier Inc.
All rights reserved.

\section{INTRODUCTION}

With technical improvement and progressive availability of brain imaging techniques, more coincidental brain lesions are being diagnosed. Often the location of these lesions is not correlated to the presenting symptoms, and surgical treatment is not indicated. Cerebrospinal fluid (CSF)containing cysts at the level of the choroidal fissure are rare embryological entities, and literature addressing them is scarce. Only one series specifically describing choroidal fissure cysts has been published (I9).

Based on our experience and a study of the literature, we discuss anatomical and embryological location, imaging characteristics, presenting symptoms, and treatment indications of these lesions.

\section{CASE SERIES}

To study the long-term outcome of patients diagnosed with a supratentorial CSF-containing cyst, we retrospectively studied the combined patient databases of the departments of neurosurgery, pediatric neurology, and neonatology. In this way we

BACKGROUND: Cerebrospinal fluid (CSF)-containing cysts at the level of the choroidal fissure are rare embryological entities infrequently described in the literature because of their benign nature. On the occasion of a case series, we present an overview of the literature and discuss anatomical and embryological location, imaging characteristics, presenting symptoms, and treatment indication of these lesions.

METHODS: We identified, in a retrospective study of a database with 81 patients harboring 86 supratentorial intracranial cysts, six patients with a CSF-containing cyst at the level of the choroidal fissure. In all cases, presenting symptoms were mild and the cysts were considered a fortuitous diagnosis. None of the patients was treated surgically, and the cysts remained stable at radiological follow-up. We performed a literature search for cerebral cysts and choroidal fissure cysts in particular.

RESULTS: Only one large study purely addressing choroidal fissure cysts was found in the literature.

CONCLUSIONS: CSF-containing cysts at the level of the choroidal fissure may be of the arachnoid or the neuroepithelial type, but pathological confirmation of a CSF-containing cyst at this specific location has never been published. Very infrequently they are symptomatic, and surgical treatment is hardly ever necessary.

identified 8I patients harboring 86 supratentorial intracranial cysts diagnosed and treated from 1984 to 2010 . We identified a subgroup of six patients with a CSF-containing cyst at the level of the choroidal fissure (7.4\%). In these six patients, the symptoms for which magnetic resonance (MR) imaging was performed varied: in three patients, a headache syndrome was the clinical problem; in one, MR was performed for learning disabilities. Other symptoms included attention deficit hyperactivity disorder (ADHD), narcolepsy, and suspicion of mild spastic paresis.

In five patients, the CSF-containing cyst was located at the level of the right choroidal fissure. All cysts were rather small $(<30$ mm diameter, Table 1) and were visualized as T2 hyperintense, Tr or fluid attenuation inversion recovery hypointense, sharply delineated lesions with or without mild compression on the surrounding brain struc- tures, but without perilesional edema. In two cases, contrast studies were performed showing absence of gadolinium enhancement. These contrast studies did illustrate the location of the cysts in relation to the choroid plexus (Figure 1).

In all patients, the cysts were regarded as insufficient to explain the presenting symptoms, and they were described as fortuitous diagnoses. Imaging follow-up in all patients, varying from a single MR scan to I8 years of follow-up with MR scans at 6 months, I year, and 2 years, demonstrated total absence of progression of the lesions. Conservative symptomatic treatment was indicated. At long-term clinical follow-up, three patients required special education because of their presenting symptoms (narcolepsy, ADHD, learning disabilities, and headache). The child with suspicion of mild spastic paresis had normal motor development at follow-up. 
Table 1. Six Patients With a Cerebrospinal Fluid-Containing Cyst at the Level of the Choroidal Fissure

\begin{tabular}{|c|c|c|c|c|c|}
\hline Patient & $\begin{array}{l}\text { Age at } \\
\text { Diagnosis } \\
\text { (months) }\end{array}$ & $\begin{array}{l}\text { Left or Right } \\
\text { Choroidal } \\
\text { Fissure }\end{array}$ & $\begin{array}{l}\text { Presenting } \\
\text { Symptoms }\end{array}$ & $\begin{array}{l}\text { Cyst Size } \\
(\mathrm{mm})\end{array}$ & $\begin{array}{l}\text { Outcome (motor } \\
\text { and educational } \\
\text { level) }\end{array}$ \\
\hline 1 & 7 & Right & $\begin{array}{l}\text { Suspicion of mild } \\
\text { spastic paresis }\end{array}$ & $32 \times 26 \times 14$ & Normal \\
\hline 2 & 84 & Right & ADHD & $16 \times 14 \times 13$ & SE \\
\hline 3 & 108 & Right & $\begin{array}{l}\text { Headache and learning } \\
\text { difficulties }\end{array}$ & $11 \times 8 \times 9$ & SE \\
\hline 4 & 180 & Right & Headache & $23 \times 17 \times 19$ & Normal \\
\hline 5 & 180 & Left & Headache & $25 \times 25 \times 18$ & Normal \\
\hline 6 & 84 & Right & Narcolepsy & $9 \times 15 \times 22$ & SE \\
\hline
\end{tabular}

\section{DISCUSSION}

\section{Embryology and Anatomy of the \\ Choroidal Fissure}

At an early embryologic stage, the cerebral hemispheres consist largely of a single cavity, the primitive lateral ventricle, enclosed by a thin wall from which the cortex of the hemispheres will develop. An asymmetric expansion of this vesicle follows, mostly upward and backward to cover and progressively overlap the diencephalon.

With the expansion of the vesicle, its cavity follows in three directions representing future lateral ventricle horns: frontal, occipital, and temporal. The roof plate of the primitive forebrain, lined with epithelium, will invaginate into the lateral ventricle via the medial wall of the hemisphere. This process leads to the formation of the choroidal fissure, which extends from the interventricular foramen to the posterior end of the primitive ventricular system.

Mesodermal tissue, carrying blood vessels with it, migrates into the invaginated fold to form the tela choroidea. The borders of the tela become more and more vascularized and form the choroid plexus, which fills a large part of the ventricular cavities in this stage. By the down and forward growth of the posterior end of the vesicle, to form the temporal lobe, the choroidal fissure finally reaches from the interventricular foramen to the extremity of the inferior horn of the ventricle $(\mathrm{I} 5,4)$.

The choroidal fissure is thus the fissure between the tenia fornicis and tenia choroidea and is located between the fornix and the thalamus in the medial part of the lateral ventricle. It is divided into three parts: (a) a corpus portion situated in the corpus of the lateral ventricle between the corpus of the fornix and the thalamus, (b) an atrial part located in the atrium of the lateral ventricle between the crus of the fornix and the pulvinar, and (c) a temporal part situated in the temporal horn between the fimbriae of the fornix and the posterior part of the internal capsule. The tela choroidea arises from the teniae, invaginates through the choroidal fissure, and passes into the temporal horn, where it gives rise to the choroid plexus (II, I2, 22). Figure 2 shows a coronal section through the thalamus and hippocampus of a left hemisphere of a dissected brain specimen demonstrating the anatomy of the choroidal fissure (Figure 2).

Differential Diagnosis of a Cystic Lesion at the Level of the Choroidal Fissure The differential diagnosis of cysts located at the level of the choroidal fissure consists mainly of arachnoid or neuroepithelial cysts; however, cystic neoplasm, (epi-) dermoid cysts, and parasitic cysts are possible. Focal temporal lobe atrophy could lead to enlargement of the choroidal fissure simulating a cyst (ig).

When the imaging diagnosis of a cystic lesion at the level of the choroidal fissure is made, the main objective is the differentiation between benign lesions such as CSFcontaining cysts and lesions with a clear indication for active treatment (cystic neoplasm or infectious cysts). The differential diagnosis can be made with computed to- mographic (CT) and MR imaging, the latter being far superior.

Cystic brain lesions can be divided into three groups based on the MR images: a CSF-like intensity pattern of water; aproteinaceous or intermediate intensity pattern; and a high-intensity pattern characteristic of hemorrhage or colloid cyst (7). In this way, CSF-containing cysts can be differentiated from other cystic lesions. Other characteristics of CSF-containing cysts include no detectable wall or associated softtissue mass, homogeneous consistency, absence of surrounding edema or gliosis, and lack of contrast enhancement (5).

Temporal intraventricular cysts can be differentiated from choroidal fissure cysts by determining the position of the choroid plexus in relation to the cyst. Choroidal fissure cysts will displace the choroid plexus laterally, whereas intraventricular cysts will displace the choroid plexus medially (I6) (Figure 3).

Differentiation between neuroepithelial and arachnoid CSF-containing cysts at the level of the choroidal fissure can only be made by histopathological examination. Because cysts located strictly at the level of the choroidal fissure are usually small and asymptomatic, they are very rarely treated surgically. Therefore, follow-up with regular imaging will be suggested. It is unknown, however, what the exact frequency of these surveillance scans should be and when follow-up can be stopped.

\section{Cyst Formation: Histopathological}

Differences Between Arachnoidal and Neuroepithelial Cysts

Although pathological confirmation of cysts at the level of the choroidal fissure has never been published, many reports are available describing arachnoidal and neuroepithelial cysts at other locations such as the cerebral parenchyma or the ventricular space.

Cyst Formation: Arachnoid Cysts. The wall of an arachnoid cyst consists of meningothelial cells lining a fibrous connective tissue membrane. Immunohistochemistry studies show expression of epithelial membrane antigen, but for neuroepithelial markers such as Glial fibrillary acidic protein and S-Ioo, they are characteristically negative (3). 

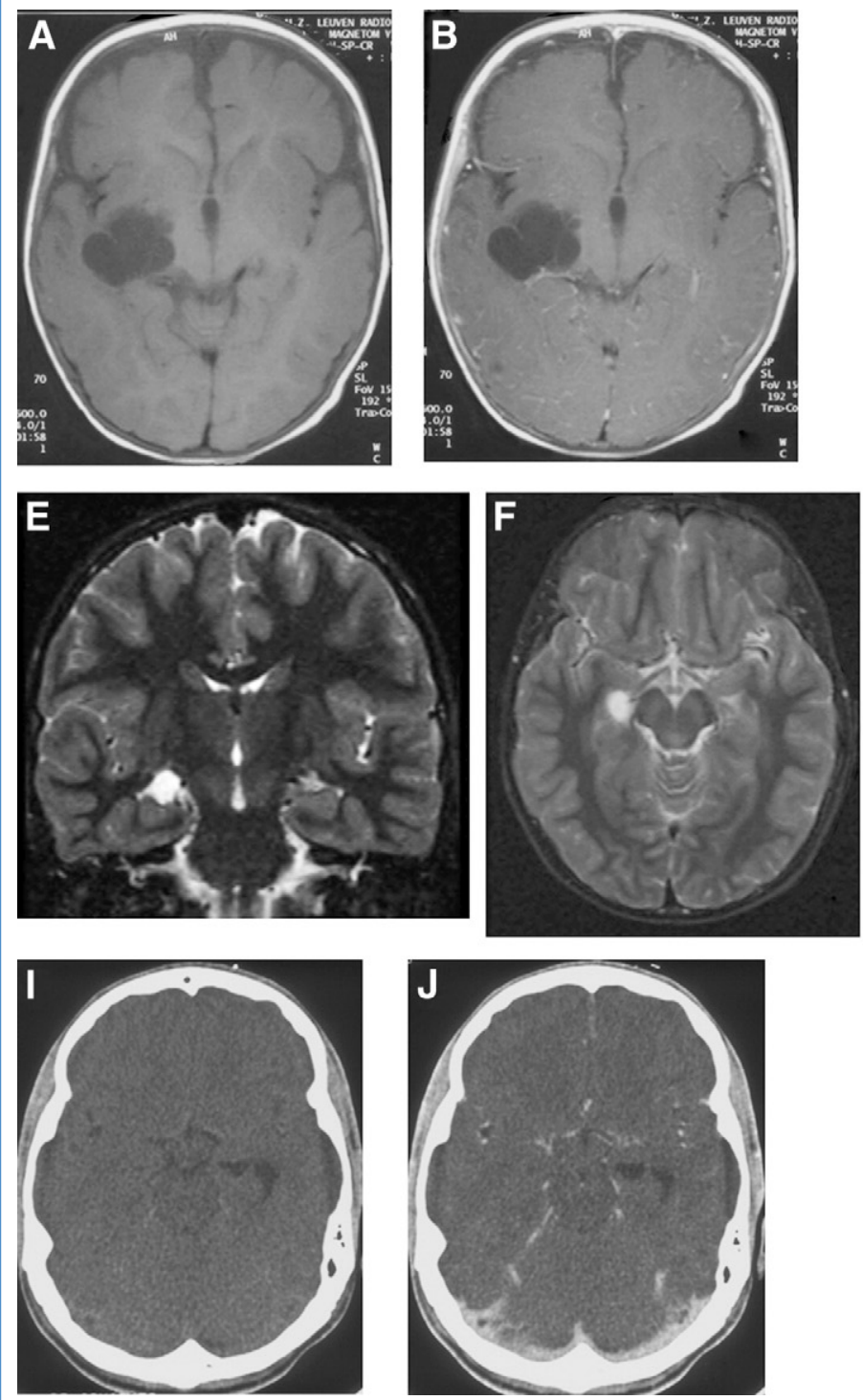

Figure 1. Patient 1 (A, B). Axial MR T1 and T1 with contrast images showing a cyst at the level of the right choroidal fissure with posterior displacement of the choroid plexus of the temporal horn and lack of gadolinium enhancement. Patient $2(\mathbf{C}, \mathbf{D})$, patient $3(\mathbf{E}, \mathbf{F})$, and patient 6 $(\mathbf{K}, \mathbf{L})$. Axial and coronal MR T1 and T2 images showing a cyst at the level of the right choroidal fissure. Patient $4(\mathbf{G}, \mathbf{H})$. Axial MR T1 and T1 with
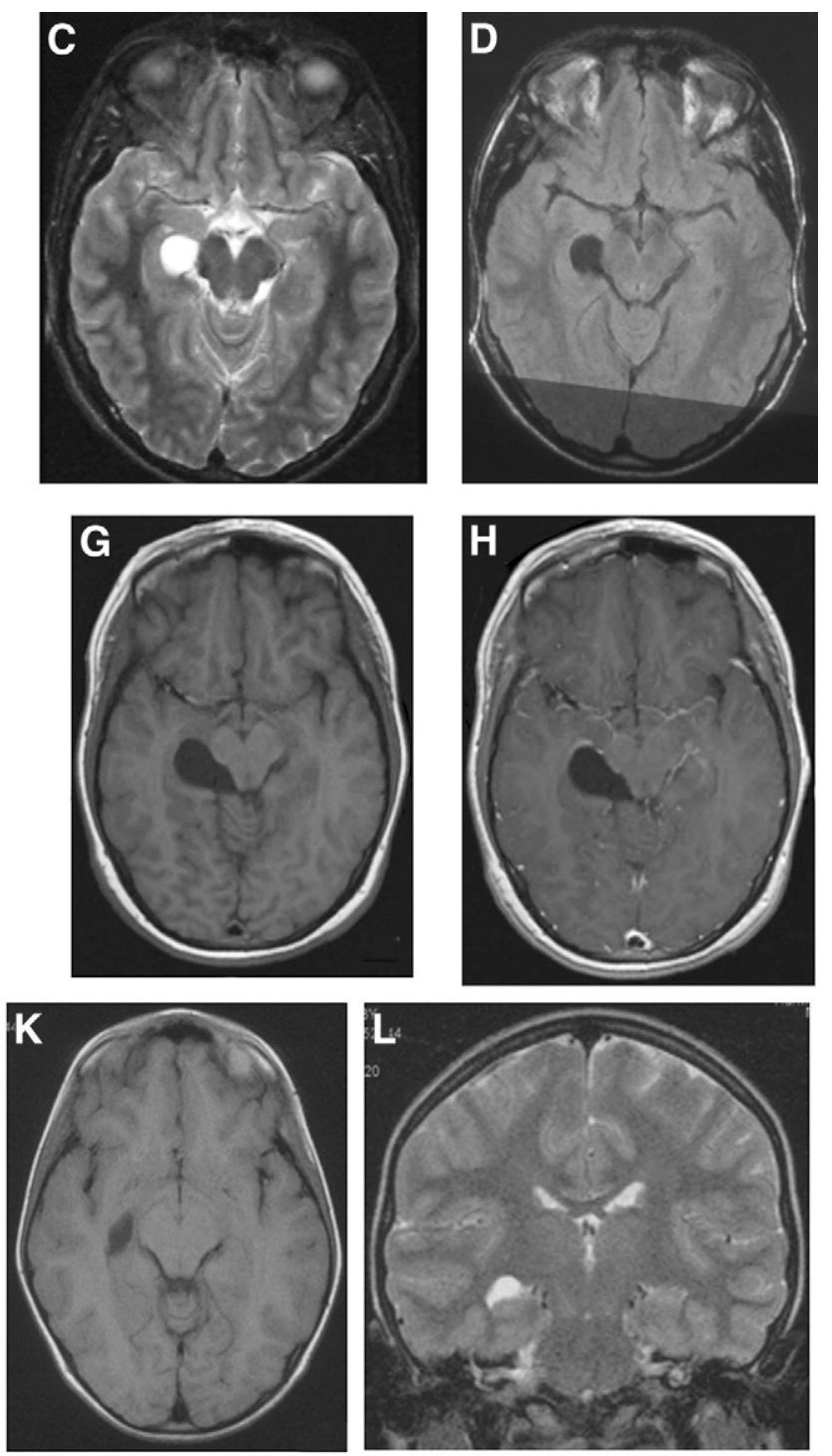

contrast images showing a cyst at the level of the right choroidal fissure communicating with the ambient cistern. There is no gadolinium enhancement, and the choroid plexus is displaced laterally. Patient 5 (I, J). Axial CT without and with contrast images showing a cyst at the level of the left choroidal fissure without contrast enhancement. CT, computed tomography; MR, magnetic resonance.
The precise mechanism of development of intracranial arachnoid cysts is still uncertain. They can be of the primary (developmental) or secondary (trauma or infection) type. There are several theories regarding the mechanism of development of primary arachnoid cysts. Starkman et al. (20) postulated that cysts form as a result of aberrant splitting and duplication in the arachnoid membrane, thus forming a cyst in the arachnoid layer. This theory has been confirmed by pathological studies that demon- strated splitting of the arachnoid membrane at the margin of the cyst (I7) and showed a distinct subarachnoid space between the cyst wall and the pia-arachnoid (8). Because most arachnoid cysts have a clear association with normal subarachnoid cisterns, it is suspected that they arise during normal arachnoid space development when fluid develops in the subarachnoid space at the $5^{\text {th }}$ week of gestation after development of the dura, arachnoid, and pia from loose primitive mesenchyme surrounding the neural tube
(I6). Another theory was offered by Robinson (I8) assuming middle cranial fossa cysts to form in response to temporal lobe agenesis, thus forming a cyst in the subarachnoid space.

For intraventricular arachnoidal cysts, other theories regarding pathogenesis have been postulated. Yeates and Enzmann (23) presented the first report of an intraventricular arachnoid cyst and stated that the cyst probably arose from the vascular mesenchyme of the primitive choroid plexus, 


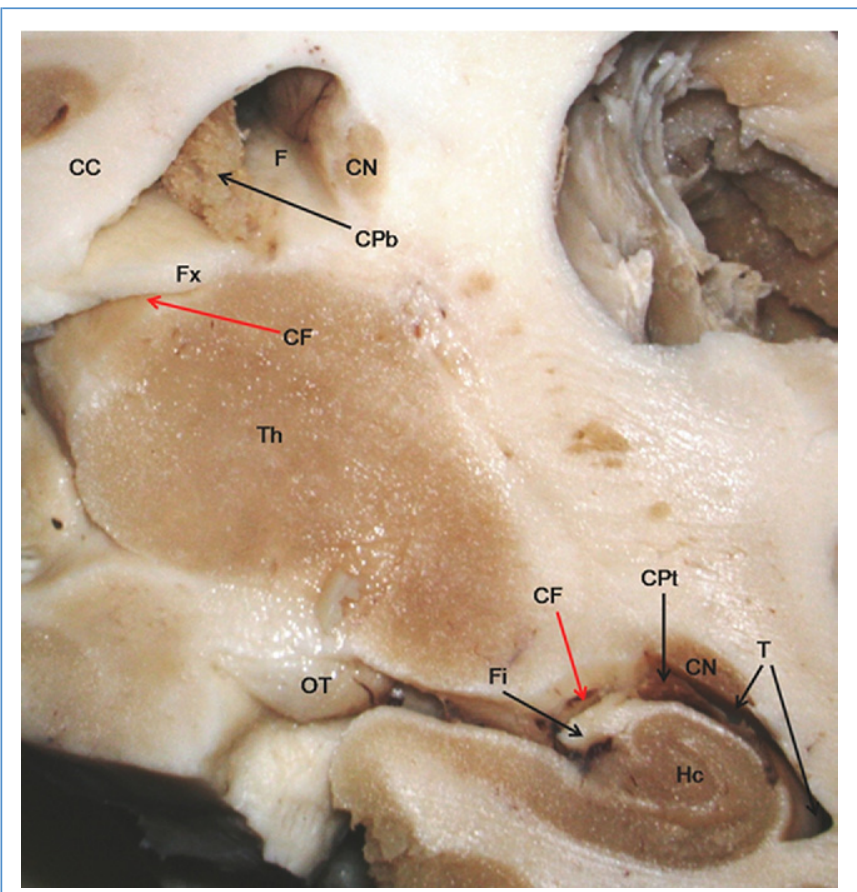

Figure 2. Coronal section through the left hemisphere. $\mathrm{CC}$, corpus callosum; CF (red arrow), choroidal fissure; $\mathrm{CPb}$, choroid plexus of the body of the lateral ventricle; $\mathrm{CPt}$, choroid plexus of the temporal horn of the lateral ventricle; $\mathrm{CN}$, caudate nucleus; $\mathrm{F}$, frontal horn (body); $\mathrm{Fi}$,

fimbrae hippocampi; Fx, fornix; Hc, hippocampus; T, temporal horn of the lateral ventricle; Th, thalamus; OT, optic tract.

which by invaginating into adjacent brain picked up an outer covering of glial tissue. In contrast to this, Nakase et al. (I4) stated that intraventricular cysts may arise from the arachnoid layer brought with the vascular mesenchyme when it invaginates via the choroidal fissure. Both theories are based on a possible defect of the normal invagination of the primitive choroid plexus into the temporal horn via the choroidal fissure. Therefore, cysts at the level of the choroidal fissure may well be arachnoidal cysts that did not migrate as far as into the temporal horn.

Cyst Formation: Neuroepithelial Cysts. Different names have been used to describe these cysts: epithelial cysts, ependymal cysts, choroid plexus cysts, choroid-epithelial cysts, epithelium-lined cysts, and subarachnoidependymal cysts. The reason for this is the heterogeneity of histopathological findings in these cysts with the uniform characteristic of a neuroepithelial lining. Expression of the normal variation of this neuroepithelium could explain the presence of cell organelles (e.g., cilia), or different cell types, within a given cyst at variable locations (3).

This regional variation has led to a division into four subcategories: (a) those arising from the primitive ectoderm: dermoid and epidermoid cysts; (b) those arising from stomodeal ectoderm, such as Rathke's cleft cysts and hypophyseal duct cysts; (c) those arising from the endoderm, including neurenteric cysts; and (d) those arising from the neuroectoderm, such as ependymal cysts and colloid cysts of the third ventricle (I).

Hirano et al. (6) suggested the term neuroepithelial cyst for structures that have the features of both primitive ependyma and choroid plexus. Most common are cysts of the choroid plexus. They are typically small and asymptomatic and are usually discovered incidentally or at autopsy. The lining is variable, but typically consists of columnar epithelium with an intact basement membrane (3). Ependymal cysts are neuroepithelial cysts, typically found in the white matter of the temporoparietal and frontal lobes. These cysts are lined by columnar or cuboidal epithelium, with or without cilia, but without a basement membrane (3).

A possible explanation of cyst formation could be "pinching off" of an ependymal diverticulum, giving rise to an isolated ependymal lined cavity without basement membrane (ependyma has no basement membrane). This is called a true ependymal cyst. An- other possibility could be sequestration of neuroectoderm and vascular pia mater creating an ependymal-like cyst (I). Located at the level of the choroidal fissure, cysts by definition have a close relationship with the choroid plexus of the temporal horn, and they may well be choroid plexus cysts.

To better understand the nature of these CSF-containing cysts, it could be suggested that cysts found at autopsy should be studied thoroughly with histopathological techniques and electron microscopy, so differentiation can be made between arachnoid or neuroepithelial cysts.

Symptomatology and Surgical Indication As mentioned earlier, solitary CSF-containing cysts at the level of the choroidal fissure are small and usually noncompressive lesions. They are almost always interpreted as a fortuitous finding, and surgical treatment is usually not necessary. The largest radiological series described by Sherman et al. (I9) underlines this. They describe 26 patients diagnosed with a cystic lesion at the level of the choroidal fissure, all asymptomatic. Five patients underwent imaging studies for complex migraine headache syndromes. In our series, three patients presented with a headache syndrome. Because solitary choroidal fissure cysts will not lead to obstruction of liquor dynamics and are not related to the meninges, their presence in patients with headache will almost always be coincidental.

Sporadically, choroidal fissure cysts may be found in patients with complex partial epileptic seizures, as described by Morioka et al. (Io) and Tamayo et al. (2I). In contrast,

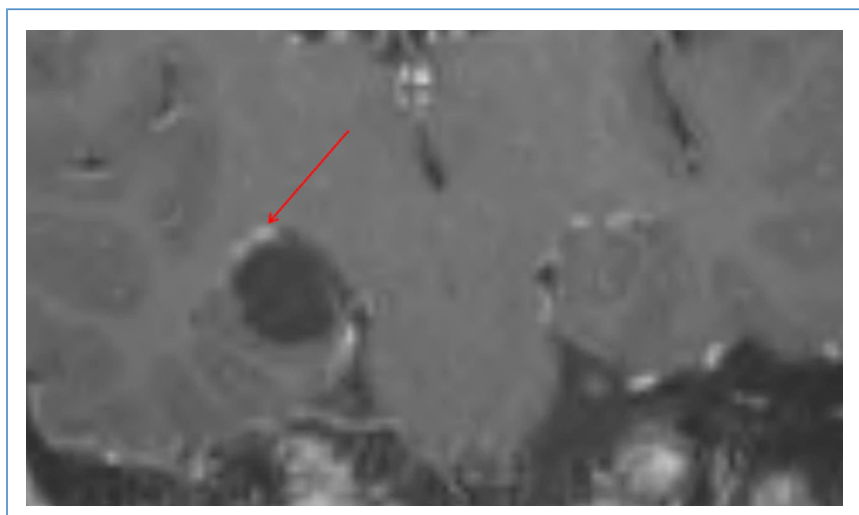

Figure 3. Coronal and enlarged $\mathrm{T} 1$ image showing a cyst medial to the displaced right choroid plexus (red arrow) excluding an intraventricular localization. 
Arroyo et al. (2) describe a series of 17 patients with epilepsy and an arachnoid cyst. Nine of these cysts were located at the level of the choroidal fissure. In seven of these patients, the epileptogenesis was not concordant with the location of the cyst. In conclusion, they suggest that these cysts are often incidental findings and do not necessarily reflect the location of the seizure focus. Sherman et al. (ig) describe five patients with a seizure disorder, none of them electroencephalographically correlated to the cyst location.

Millichap (9) describes three patients with a temporal arachnoid cyst, one of them being a choroidal fissure cyst, presenting with ADHD. He suggests a relationship between the cysts and ADHD because of the associated learning and language disabilities that may be explained by temporal lobe and Sylvian region pathology. In these cases, other causes of ADHD were ruled out. All patients were treated nonsurgically. In our series, one patient with a CSF-containing cyst in the right choroidal fissure presented with ADHD. His disorder was treated with methylphenidate, and the cyst was considered not responsible for his symptoms.

One of our patients presented with narcolepsy and subsequent learning difficulties. Nakano and Ogashiwa (13) describe an arachnoid cyst in the cerebellopontine angle and complete remission of narcolepsy after surgical treatment. Lesions in the brainstem or diencephalon have been described as a cause of narcolepsy. No relationship between a choroidal fissure cyst and narcolepsy has ever been suggested. In our case, the choroidal fissure cyst was also deemed asymptomatic.

\section{CONCLUSIONS}

CSF-containing cysts at the level of the choroidal fissure are embryological lesions that are rarely described in the literature because of their benign nature and tendency to be asymptomatic. They can be of the arachnoid type, and they are probably similar entities as the rarely described intraventricular arachnoid cysts that do not migrate as far as into the temporal horn. They could also be of the neuroepithelial type. Because of the close relationship with the choroid plexus of the temporal horn, they might be choroid plexus cysts. All six cases of CSF-containing cysts in our series were considered a fortuitous diagnosis, and surgical treatment was not considered.

\section{REFERENCES}

I. Andrews BT, Halks-Miller M, Berger MS, Rosenblum ML, Wilson CB: Neuroepithelial cysts of the posterior fossa: pathogenesis and report of two cases. Neurosurgery I5:9I-95, I984.

2. Arroyo S, Santamaria J: What is the relationship between arachnoid cysts and seizure foci? Epilepsia 38:1098-I102, I997.

3. Boockvar JA, Shafa RBA, Forman MS, O'Rourke DM: Symptomatic lateral ventricular ependymal cysts: criteria for distinguishing these rare cysts from other symptomatic cysts of the ventricles: case report. Neurosurgery 46:1229-1233, 2000.

4. Gray's Anatomy of the Human Body. Twentieth Edition. Available at: www.bartleby.com. Accessed July I, 2010.

5. Guermazi A, Miaux Y, Majoulet JF, Lafitte F, Chiras J: Imaging findings of central nervous system neuroepithelial cysts. Eur Radiol 8:618-623, 1998.

6. Hirano A, Ghatak NR, WisoffHS, Zimmerman HM: An epithelial cyst of the spinal cord: an electron microscopic study. Acta Neuropathol (Berl) I8:214223, I97I.

7. Kjos BO, Brant-Zawadzki M, Kucharezyk W, Kelly WM, Norman D, Newton TH: Cystic intracranial lesions: magnetic resonance imaging. Radiology I55:363-369, I985.

8. Krawchenko J, Collins GH: Pathology of an arachnoid cyst. J Neurosurg 50:224-228, I979.

9. Millichap JG: Temporal lobe arachnoid cyst-attention deficit disorder syndrome: role of the electroencephalogram in diagnosis. Neurology 48:1435I439, I997.

Io. Morioka T, Nishio S, Suzuki S, Fukui M, Nishiyama T: Choroidal fissure cyst in the temporal horn associated with complex partial seizure. Clin Neurol Neurosurg 96:164-167, I994.

II. Naidich TP, Daniels DL, Haughton VM, Pech P, Williams A, Pojunas K, Palacios E: Hippocampal formation and related structures of the limbic lobe: anatomic-MR correlation part II. Sagittal Sections. Radiology I62:755-761, I987.
I2. Naidich TP, Daniels DL, Haughton VM, Williams A, Pojunas K, Palacios E: Hippocampal formation and related structures of the limbic lobe: anatomic-MR correlation part I. Surface features and coronal sections. Radiology 162:747-754, I987.

I3. Nakano H, Ogashiwa M: Complete remission of narcolepsy after surgical treatment of an arachnoid cyst in the cerebellopontine angle. J Neurol Neurosurg Psychiatry 58:264, I995.

I4. Nakase $H$, Hisanaga $M$, Hashimoto $S$, Imanishi $M$, Utsumi S: Intraventricular arachnoid cyst: report of two cases. J Neurosurg 68:482-486, I988.

15. Nieuwenhuys R, Voogd J, van Huijzen C: The Human Central Nervous System: Development. $4^{\text {th }}$ edition. Berlin: Springer; 2008.

I6. Park SW, Yoon SH, Cho KH, Shin YS: A large arachnoid cyst of the lateral ventricle extending from the supracerebellar cistern: case report. Surg Neurol $6_{5}$ : 6II-6I4, 2006.

17. Rengachary SS, Watanabe I: Ultrastructure and pathogenesis of intracranial arachnoid cysts. J Neuropathol Exp Neurol 40:6I-83, I98I.

I8. Robinson RG: Congenital cysts of the brain: arachnoid malformations. Prog Neurol Surg 4:133-174, I97I.

I9. Sherman JL, Camponovo E, Citrin CM: MR imaging of CSF-like choroidal fissure and parenchymal cysts of the brain. Am J Neuroradiol II:939-945, I990.

20. Starkman SP, Brown TC, Linell EA: Cerebral arachnoid cysts. J Neuropathol Exp Neurol 17:484-500, 1958 .

2I. Tamayo JA, Ojea T, Hervás M, León A, Fernández O: Neuroepithelial cyst of the choroid sulcus as a probable cause of symptomatic focal epilepsy. Rev Neurol 25:2070-207I, I997.

22. Wen HT, Rhoton AL Jr, De Oliveira E: Transchoroid approach to the third ventricle: an anatomic study of the choroidal fissure and its clinical application. Neurosurgery 42:1205-1219, 1998.

23. Yeates A, Enzmann D: An intraventricular arachnoid cyst. J Comput Assist Tomogr 3:697-700, I979.

Conflict of interest statement: The authors declare that the article content was composed in the absence of any commercial or financial relationships that could be construed as a potential conflict of interest.

received 19 July 2010; accepted 17 December 2010

Citation: World Neurosurg. (2011) 75, 5/6:704-708.

DOl: 10.1016/j.wneu.2010.12.056

Journal homepage: www.WORLDNEUROSURGERY.org

Available online: www.sciencedirect.com

1878-8750/\$ - see front matter (C) 2011 Elsevier Inc.

All rights reserved.

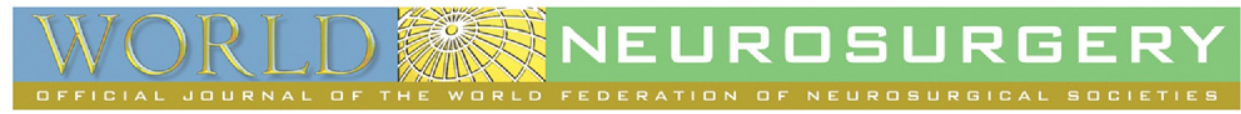

